\title{
FATIGUE PERF0RMANCE OF 6063-T66 ALUMINUM ALLOY UNDER COMBINED CYCLIC LOADING OF PARENT AND WELDED SPECIMENS
}

The article deals with the determining of fatigue lifetime of structural materials during multiaxial cyclic loading. The aim of this investigation is to evaluate the influence on fatigue behavior of the welded aluminum alloy EN AW 6063-T66. Experimental device was designed for combined bending - torque loading. The experimental part was focused on the modeling of combined biaxial loading and determining the number of cycles to fracture in the region of low-cycle fatigue. In-phase loading can be treated fairly well using the conventional hypotheses (von Mises or Tresca) on basis of nominal, structural or local strains or stresses. Based on the experimental results the fatigue design curves are compared to fatigue data from base metal and weldments.

Keywords: Multiaxial fatigue, computational analysis, experimental analysis, torsion loading, bending loading, stress analysis, strain analysis, aluminum alloy, welding

\section{Introduction}

Fatigue failure is an extremely complex physical process which is governed by a great number of parameters related to, for example, local geometry and material properties of the structural region surrounding the crack growth path. It is commonly recognized that it is impossible for a physical model to account for all fatigue influencing parameters, thus a lot of approximate models have been conceived for practical fatigue assessments. In every stadium of fatigue cumulative damage dominates a definite mechanism controlled by more or less known and verified rules [1]. There exists a stage of micro-plastic process in the total volume of material with a following stage of fatigue crack nucleation and stage of their growing with a more or less detailed zoning. Despite of this research no results have been achieved, which could be considered as successful ones. This applies mainly to the cases of random and combined stress, where today's procedures used in one axis stress analysis fail. Fatigue under combined loading is a complex problem. A rational approach might be considered again for fatigue crack nucleation at the material surface [2]. The state of stress at the surface is two-dimensional because the third principal stress perpendicular to the material surface is zero. Another relatively simple combination of different loads is offered by an axle loaded under combined bending and torsion. This loading combination was tested in our and also in many others experiments [3, 4]. In spite of this fact, fatigue mechanisms are still not fully understood. This is partly due to the complex geometrical shapes and also complex loadings of engineering components and structures which result in multiaxial cyclic stress-strain states rather than uniaxial.
The strength analysis of welded structures does not deviate much from that for other types of structures. Various failure mechanisms have to be avoided through appropriate design, choice of material, and structural dimensions. Design criteria such as yielding, buckling, creep, corrosion, and fatigue must be carefully checked for specific loading conditions and environments. It is, however, the fact that welded joints are particularly vulnerable to fatigue damage when subjected to repetitive loading. Fatigue cracks may initiate and grow in the vicinity of the welds during service life even if the dynamic stresses are modest and well below the yield limit. The problem becomes very pronounced if the structure is optimized by the choice of high strength steel. The very reason for this choice is to allow for higher stresses and reduced dimensions, taking benefits of the high strength material with respect to the yield criterion. However, the fatigue strength of a welded joint is not primarily governed by the strength of the base material of the joining members; the governing parameters are mainly the global and local geometry of the joint. Hence, the yield stress is increased, but the fatigue strength does not improve significantly. As already stated, the fatigue behavior of welded joints is random by nature. Very few loadbearing details exhibit such large scatter in fatigue life as welded joints. This is true even in controlled laboratory conditions. As a consequence, it becomes an important issue to take scatter into consideration, both for the fatigue process and for the final life. Furthermore, the in-services stresses may often be characterized as stochastic processes $[5,6]$.

The general issues described above are, of course, also important for welded joints. However, a welded joint has some peculiar

\footnotetext{
* Peter Kopas, Milan Saga, Milan Uhricik

Department of Applied Mechanics, Faculty of Mechanical Engineering, University of Zilina, Slovakia, E-mail: peter.kopas@fstroj.uniza.sk
} 
features that make some of the subjects and parameters play a much more important role than others $[7,8]$. Let us start with an S-N curve for a welded joint and compare it with other specimens. Figure 1 shows the S-N curves based on tests with one smooth plate, one plate with a bore hole, and one plate with a fillet welded transverse attachment. This type of fillet welded joint is often referred to as non-load-carrying due to the fact that the load is carried straight through the base plate. It is also noted that the applied force is transverse to the welding direction [9]. In the plate the fatigue cracks can appear anywhere in the longitudinal edges of the plate, whereas they will appear at the inner edges of the bore hole transverse to the applied loading in the specimen with the hole. The latter phenomenon is due to the stress concentration at the edge of the hole. In the fillet welded joint the cracks will appear at the weld toe and grow through the base plate in a direction perpendicular to the applied principal stresses. The cracks are indicated on the specimens in Fig. 1. The cracks may emanate from several spots along the weld seam. Small semi-elliptical-shaped cracks are formed, grow, and coalesce to become larger cracks. In the final stage the remaining ligament of the plate section is too small to carry the peak load.

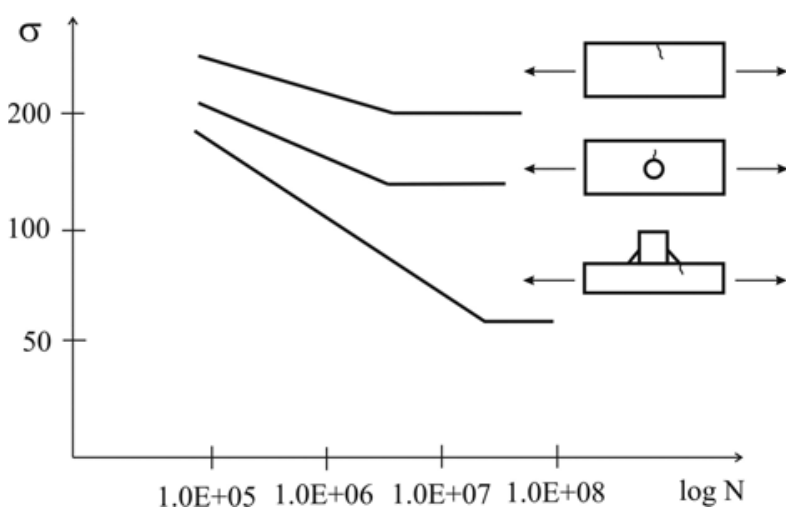

Fig. 1 Fatigue life curves for various details [8]

The difference between the S-N curve for the specimen with the hole and the S-N curve for the welded joint is rather surprising considering the fact that the bore hole creates a stress concentration factor close to 3 at the edge of the hole. The relatively short fatigue life of welded detail is explained, in the main, by three factors:

- severe notch effect due to the attachment and the weld filler metal,

- presence of non-metallic intrusions or micro-flaws along the fusion line,

- presence of large tensile residual stresses.

\section{Test equipment design}

The design of experimental equipment is based on a mechanical principle (Fig. 2). The constant rotation is generated by excen- ter and linkage mechanism. By changing of excentric magnitude it is possible to change a loading magnitude. Also if we change the length of connecting crank on the experimental equipment, there will be a change in the loading cycle character (proportional-nonproportional loading, bending/torsion loading, etc.) [10]. Power of the device is secured by two synchronic electromotors with frequency converters from $0.5 \mathrm{~Hz}$ to $100 \mathrm{~Hz}$. Loading frequencies are identical with the frequency of rotation drive. Synchronization of the electromotors is secured by electronics and allows synchronization of the loading amplitude. The synchronization of electromotors also allows setting the phase shift for individual loading levels. There are also two force measurement systems included in the experimental equipment. These systems may be used for measurement of force values during the loading process. For evaluation of fatigue curves it is necessary to know stress and strain conditions on individual loading levels [11].

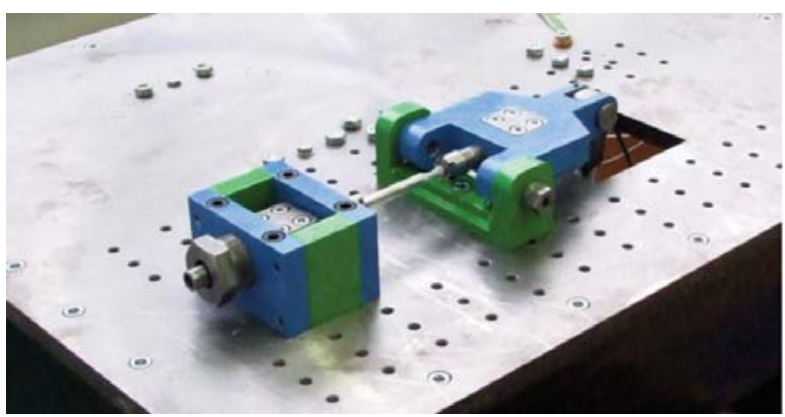

a) real equipment

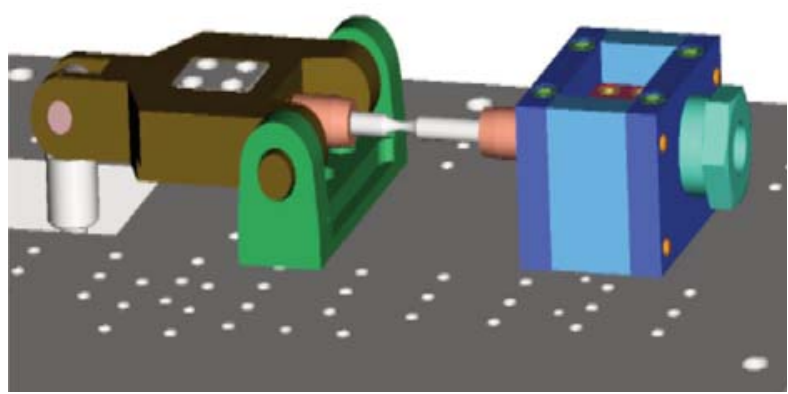

b) virtual equipment

Fig. 2 Mutiaxial fatigue loading system

\section{Material characteristics}

This research was conducted on an AlMgSi07.F25 aluminum alloy: the EN AW 6063-T66 aluminum alloy. The EN AW 6063T66 is a medium strength alloy suitable for applications where no special strength properties are required. Complex shapes can be produced with very good surface quality characteristics, and suit- 


\begin{tabular}{|c|c|c|c|c|c|c|c|c|c|c|}
\hline \multirow{2}{*}{$\mathrm{Si}$} & \multirow{2}{*}{$\mathrm{Fe}$} & \multirow{2}{*}{$\mathrm{Cu}$} & \multirow{2}{*}{$\mathrm{Mn}$} & \multirow{2}{*}{$\mathrm{Mg}$} & \multirow{2}{*}{$\mathrm{Cr}$} & \multirow{2}{*}{$\mathrm{Zn}$} & \multirow{2}{*}{$\mathrm{Ti}$} & \multicolumn{2}{|c|}{ Other } & \multirow{2}{*}{$\mathrm{Al}$} \\
\hline & & & & & & & & Each & Total & \\
\hline $0.20-0.60$ & 0.35 & 0.10 & 0.10 & $0.45-0.90$ & 0.10 & 0.10 & 0.10 & 0.05 & 0.15 & rest \\
\hline
\end{tabular}

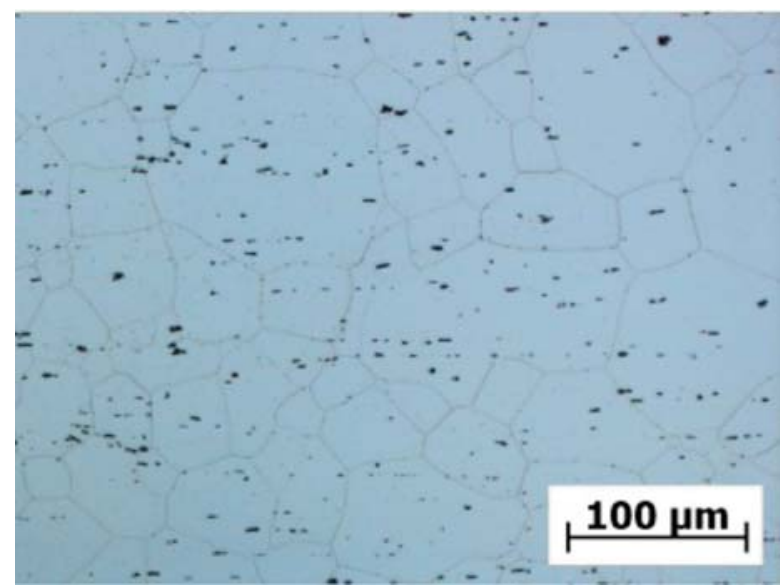

Fig. 3 Microstructure of the EN AW 6063-T66 aluminum alloy according to the rolling direction, etch. $0.5 \% \mathrm{HF}$

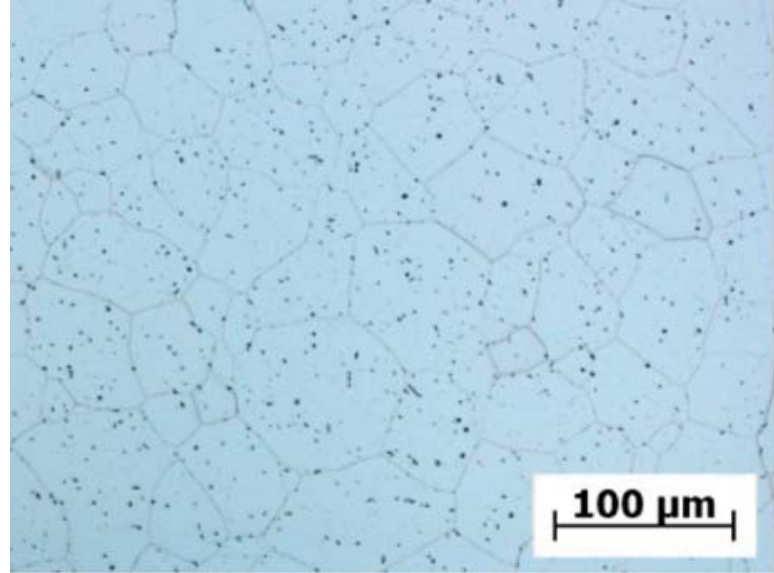

Fig. 4. Microstructure of the EN AW 6063-T66 aluminum alloy transversal rolling direction, etch. $0.5 \% \mathrm{HF}$ able for many coating operations such as anodizing and powder coating. The T66 treatment corresponds to solution heat-treated and then artificially aged (precipitation hardened) to a higher level of mechanical properties through special control of a manufacturing process. Such heat treatment conditions make mechanical property level higher than T6 heat treatment conditions. The typical chemical composition of the EN AW 6063-T66 aluminum alloy is shown in Table 1. The material used in this research was delivered in the form of a cylindrical shape with a diameter $10 \mathrm{~mm}$. The length of cylindrical bars was $150 \mathrm{~mm}$. The material was in a rolled state.

Figs. 3 and 4 illustrate a typical microstructure of the aluminum alloy evaluated in the longitudinal and transversal directions. Stretched grains are visible due to the rolling process. Also, a dispersed second phase typical of deformed and heat treated wrought aluminum alloys is observed.

Welding was conducted by the tungsten-inert gas (TIG) welding method using a Fronius Magic Wave 2200 welding machine. The

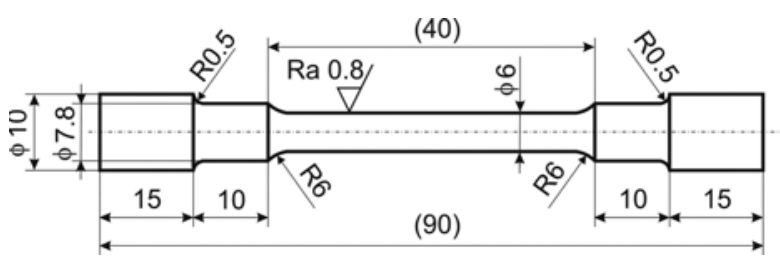

Fig. 5 Shape and dimension of tensile test specimen (dimension in $\mathrm{mm}$ ) used welding factors were: welding current $I_{z}=79$ A; welding voltage $U_{z}=18.8 \mathrm{~V}$; diameter of a wolfram electrode $\emptyset=2.4 \mathrm{~mm}$; welding gas $\mathrm{Ar} 99.996 \%$ with gas flow $Q=151 . \mathrm{min}^{-1}$. Aluminum wire $\mathrm{AlSi}_{5}$ with diameter $\emptyset=2 \mathrm{~mm}$ was used as welding wire material. The joint strength of TIG-welded joints was evaluated by tensile testing and fatigue testing, using the test specimens shown in Figs. 5 and 6. The hardness distribution of joints was measured along the axial center, at the weld interface and at the original material zone using a Brinell hardness tester (HBW).

The static tensile test with standard specimens performed before and after the welding process was also carried out. The results are summarized in Tab. 2. The stress-strain diagram contains engineering stresses and true stresses depending upon strain (Fig.7). For FEM analyses by ADINA true stresses were useful. Join geometry of the rod used for the welding process is shown in Fig. 8. Fig. 9 illustrates the final shape of a welded joint.

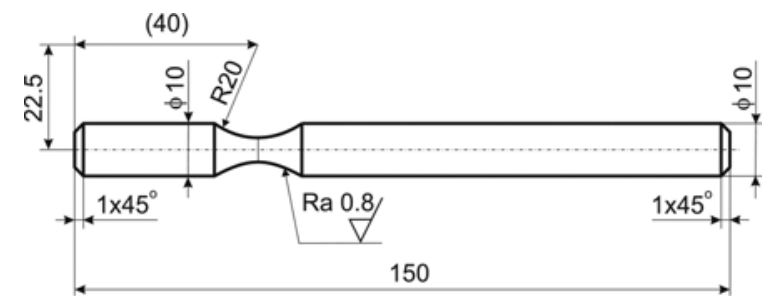

Fig. 6 Shape and dimension fatigue test specimen (dimension in $\mathrm{mm}$ ) 
Mechanical properties of the EN AW 6063-T66 aluminum alloy

\begin{tabular}{|l|l|}
\hline Young modulus & $62500 \mathrm{MPa}$ \\
\hline Ultimate tensile strength & $247 \mathrm{MPa}$ \\
\hline Tensile yield strength & $212 \mathrm{MPa}$ \\
\hline Ultimate tensile strength of welded specimen & $166 \mathrm{MPa}$ \\
\hline Tensile yield strength of welded specimen & $79 \mathrm{MPa}$ \\
\hline
\end{tabular}

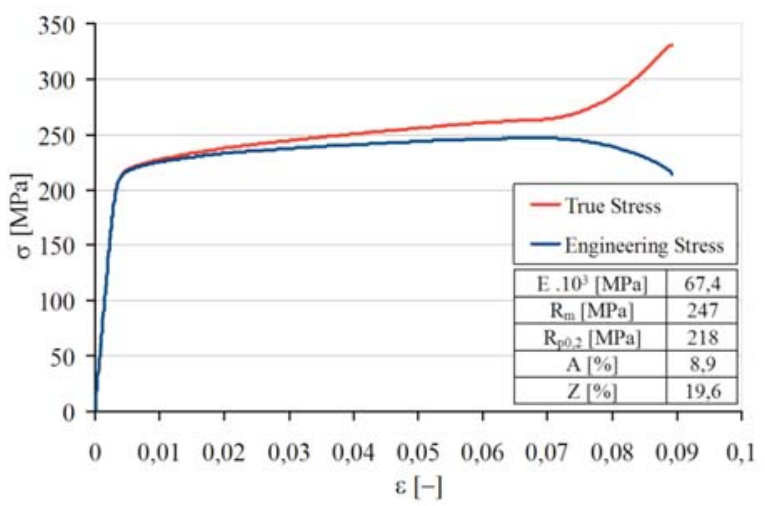

Fig. 7 Stress-strain graph for EN AW 6063

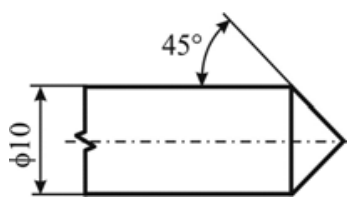

Fig. 8 Joint geometry (dimension in $\mathrm{mm}$ )

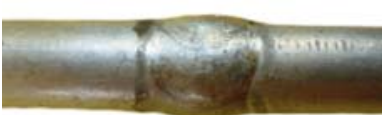

Fig. 9 Shape of welded joint

\section{Experimental and numerical strain-life data results}

Thirty smooth specimens were tested under strain controlled conditions in order to identify the strain-life behavior of the experimental material. After machining, the specimen surfaces were mechanically polished. The experiments were carried out in an electro mechanic fatigue test machine, developed at the University of Zilina. A sinusoidal waveform was used as command signal. The fatigue tests were conducted with constant strain amplitudes, at room temperature. The specimens were cyclically loaded under strain control with a symmetrical proportional bending-torsion loading, with a nominal strain ratio, $R=-1$. The computational fatigue tests were performed under in-phase cyclic loading with the zero mean value. All tests were performed under controlled bending and torsion moments. The frequency of each analysis was equal to $30 \mathrm{~Hz}$.
The results, fatigue resistance (strain amplitude vs. number of cycles to failure) of tested structural material EN AW 6063-T66 before and also after the welding process (TIG) in the low cycle regime are presented in Figs. 10 and 11. In the low cycle regime of loading the strain amplitude decreases with the increasing number of cycles to failure for both series of aluminum alloy.

The first series of performed experiments (without a welding joint) were to verify fatigue behavior of low-cycle bending and lowcycle torsion loading to obtain relation between strain magnitudes versus number of cycles to failure. The second series of performed experiments (with a welding joint) were to also verify fatigue behavior of aluminum alloy EN AW 6063-T66 under low-cycle bending and torsion loading to obtain relation between strain magnitudes versus number of cycles to failure. Fig. 10 shows the results of fatigue tests with the symmetrical pure bending loading for the base material in comparison with welded joints. The specimen failure criterion during the testing was focused on the creation of fracture area more than $90 \%$ in the measured cross section of the testing rod for both series.

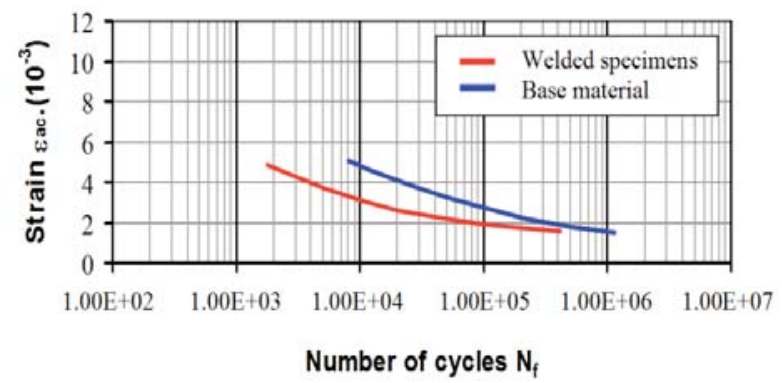

Fig. 10 Manson-Coffin curves for uniaxial low-cycle bending fatigue with phase shift $0^{\circ}$

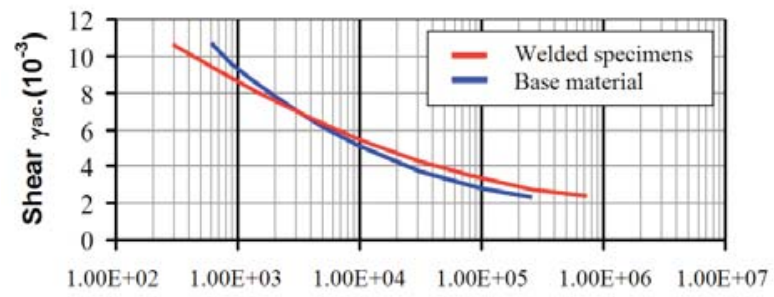

Number of cycles $\mathrm{N}_{\mathrm{f}}$

Fig. 11 Manson-Coffin curves for uniaxial low-cycle torsion fatigue with phase shift $0^{\circ}$

For fatigue test interpretation on each loading levels it is necessary to know the plastic strain amplitude (Manson-Coffin curve) or stress amplitude (Wohler curve) applied on each cycle loading level. For that it is necessary to analyze the stress and strain maximum values by FEM [12]. The specimen model was created by the finite-element program ADINA (see Fig. 12). 


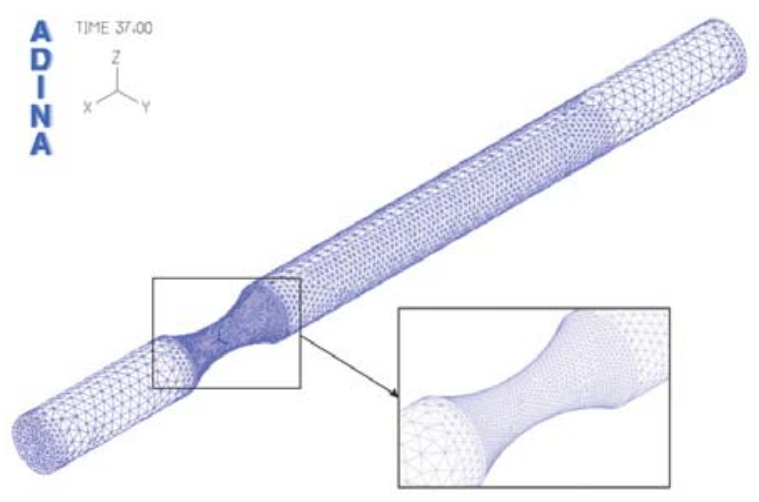

Fig. 12 Finite element model of modeled specimen

The material was assumed plastic-bilinear; the true stresses were obtained from a real stress-strain graph in Fig. 7. The tetrahedron linear element type was automatically generated. The "Load Plot" function was defined by excenter setting with excentricity $1 \mathrm{~mm}$ or $2 \mathrm{~mm}$. At the fix point shell and beam elements were used for hammer simulating.

From the computational analysis can be seen that the area with the greatest concentration of stresses or the place with the higher deformation was localized in the middle of the rod radius (see Fig. 13).

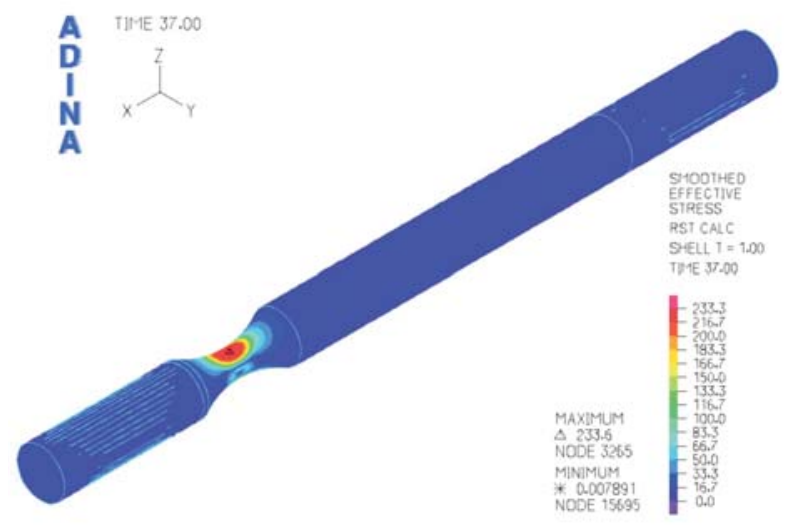

Fig. 13 Result of FEM analysis

The welding process can be simulated by numerical analyses and the obtained results (thermal field, material structure, hardness, plastic deformation, stress and strain of structure) can be used to perform effective numerical technology and manufacture process optimization. The welding simulation finite element software SysWeld will be used to solve that problem.

It belongs to the top world computational programs for full coverage to solve the welding joint problem. SysWeld was useful at the welding simulation process and also at the residual stress determination. Accurate and reliable residual stress prediction and measurements are essential for structural integrity and fatigue assessment of components containing residual stresses. Simulation of the manufacturing process using finite element technique is an accepted method for predicting the residual stresses. However, finite element simulation of residual stresses due to welding involves in general many phenomena, e.g. non-linear temperature dependent material behavior, 3D nature of the weld pool and the welding processes and microstructural phase transformation. Despite the simplification by excluding various effects, welding simulations is still CPU time demanding and complex. Hence, simplified 2D welding simulation procedures are required in order to reduce the complexity and thus maintain the accuracy of the residual stress predictions. However, the residual stress distribution for a complex welded structure is usually not known and conservative assumptions are made of the residual stress distribution when linear elastic fracture mechanics (LEFM) fatigue life predictions are carried out. The results of the residual stress and strain characterization are shown in Figs. 14 and 15.

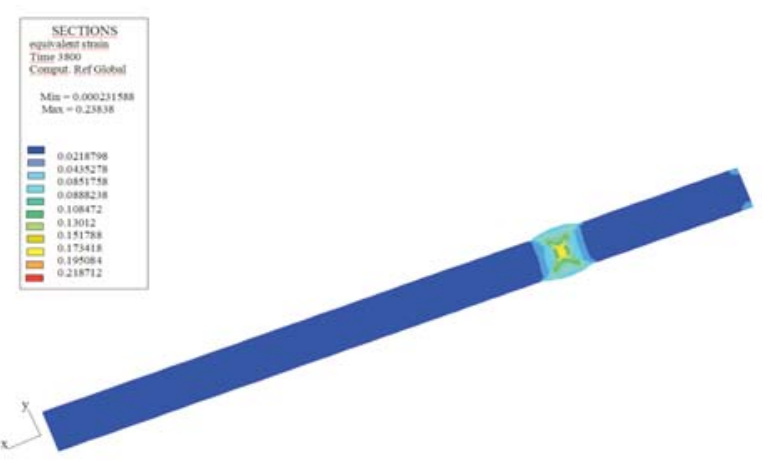

Fig. 14 Equivalent strain at the cutting plane

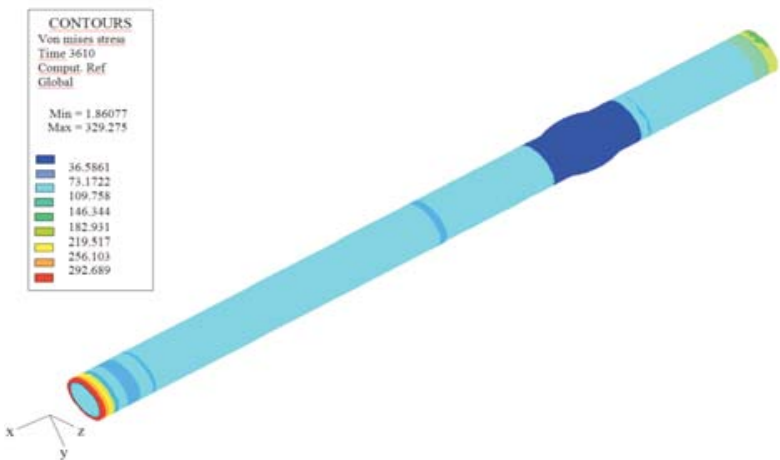

Fig. 15 Von Mises stress at the sample after snap unfix

Fig. 14 shows deformations on the top surface of the weld. To this goal it was necessary to apply a cutting plane at the welded specimen and to show deformations inside the specimen (see Fig. 
15). The maximum strains outside the tick gripping are at the center of the welded joint on the meltdown border. The results of the numerical simulation have shown to presence the plastic deformation. It means that the thermal area was powerful enough for creation of residual stresses at the material.

\section{Conclusion}

Generally we can say that the results are in good agreement with the results published by other authors [2-6]. The differences in fatigue resistance of aluminum alloy of both series of specimens are caused by different type of loading. Fatigue under cyclic bending is not that much different in comparison with fatigue results under cyclic torsion of loading. Multiaxial fatigue strength of the welded specimens decreased in comparison with parental material, EN AW 6063-T66. The decrease in fatigue strength of the welded specimens was attributed to the stress concentration at the toe of weld.

Residual stress is an important factor influencing the structural behavior in all instability failures as well as in fatigue crack initiation and propagation when cyclic service stresses are superposed onto the residual stresses. Residual stress at the weld point was $40 \mathrm{MPa}$. Residual stresses are present in many fabricated structures due to local plastic deformation from hermal and mechanical operations during the manufacturing. The presence of residual stresses in engineering components and structures can significantly affect the fatigue behavior during external cyclic loading. The effect of residual stresses may either be beneficial or detrimental, depending on magnitude, sign and distribution of the stresses with respect to the loadinduced stresses. Residual stresses in tension are detrimental and are often in the magnitude of the materials yield strength. The tensile residual stresses will reduce the fatigue life of the structure by increasing the growth of the fatigue crack, while compressive residual stresses will decrease fatigue crack growth rate. The existence of tensile residual stresses in a surface layer accelerates crack initiation reducing fatigue life due to the increase of local mean stress. An improvement in the fatigue life of the welded joints can be related to the fact that generally the T66 heat treatment produces an almost completely relief of tensile residual stresses in aluminum alloy weldments. Therefore the slope of fatigue curves in Figs. 10 and 11 are similar.

\section{Acknowledgements}

This work has been supported by VEGA grant No. 1/1089/11 and No. 1/0125/09.

The authors gratefully acknowledge this support.

\section{References}

[1] TREBUNA, F., BURSAK, M.: Medzne stavy, lomy [Limiting States and Fractures]. Grafotlac, Presov, 2002. ISBN 807165-362-4.

[2] LEGER, J.: Fatigue Life Testing of Crane Drive Shafts under Crane-Typical Torsional and Rotary Bending Loads. Schenck Hydropuls Mag., No. 1, pp. 8-11, 1989.

[3] BANNANTINE, J. A., SOCIE, D. F.: A Multiaxial Fatigue Life Estimation Technique. In: Advances in Fatigue Lifetime Predictive Techniques, ASTM STP 1122. Eds: M. R. Mitchell a R. W. Landgraf. Philadelphia, American Society for Testing and Materials, pp. 249-275, 1992.

[4] GOUGH, H. J., POLlARD, H. V.: Some Experiments of the Resistance of Metals to Fatigue under Combined Stresses, Part I., Min. of Supply, Aero Res. Council, RSM 2522, 1951.

[5] MATHERS, G.: The Welding of Aluminium and its Alloys. Published by Woodhead Publishing Limited, Abington Hall, Abington Cambridge CB1 6AH, England, ISBN 0-8493-1551-4, 2002.

[6] BLATNICKY, M.: Doctoral thesis. University of Zilina, 2011.

[7] ZMINDAK, M., NOVAK, P., MESKO, J.: Numerical Simulation of arc Welding Processes with Metallurgical Transformations. Metallurgy, vol. 49, No. 2, pp. 595-599, ISSN 0543-5846, 2010.

[8] SAPIETOVA A., DEKYS V., VASKO M.: A Numerical Model of Rotating Machine Having Unbalance and the Measurements of its Dynamical Properties. Metalurgija (Metallurgy), vol. 49, No. 2, pp. 503-507, ISSN 0543-5846, 2010.

[9] MADDOX, S. J.: Fatigue Strength of Welded Structures, Second Edition, Woodhead Publishing, UK, ISBN 978-1855730137, 1991.

[10] JAKUBOVICOVA, L., KOPAS, P., HANDRIK, M., VASKO, M.: Computational and Experimental Analysis of Torsion and Bending Loading of Specimen. Intern. Conference on Innovative Technologies, Prague, pp. 395-400, ISBN 978-80-904502-2-6, 2010.

[11] SAGA M., KOPAS P., VASKO M.: Some Computational Aspects of Vehicle Shell Frames Optimization Subjected to Fatigue Life. Communications - Scientific Letters of the University of Zilina, vol. 12, No. 4, pp. 73-79, ISSN 1335-4205, 2010.

[12] BATHE, K. J.: Finite Element Procedures. New Jersey, Prentice Hall, 1982. 